\title{
Assessment of suicidal risk using Minnesota multiphasic personality inventory-2 restructured form
}

\author{
Sunhae Kim", Hye-Kyung Lee ${ }^{2}$ and Kounseok Lee ${ }^{1 *}$ (D)
}

\begin{abstract}
Background: Suicide is a major social issue, affected by both social and psychopathological factors. This study investigated suicide risk assessment using the Minnesota Multiphasic Personality Inventory-2 Restructured Form (MMPI-2-RF).
\end{abstract}

Methods: Data were collected from 7824 college students using the MMPI-2-RF. The participants were classified into high-, moderate-, and low-risk for suicide groups based on their scores on the structured Mini-International Neuropsychiatric Interview (MINI) for comparative analysis. The relationships between scores on the Restructured Clinical (RC) Scales of the MMPI-2-RF and suicide risk level were investigated using a multiple logistic regression.

Results: Out of the 7824 participants, 964 (12.3\%) were identified as being at risk of suicide. There were 553 participants considered low-risk, 312 moderate-risk, and 99 at high-risk. Suicide risk in the participants tended to increase as RC scale scores increased. Out of the nine RC scales, the Demoralization (RCd) and Negative Emotions (RC7) scale scores were highest across all risk groups. The results of a multiple logistic regression indicated that the Demoralization (RCd) scores were significantly elevated in all three suicide risk groups. Antisocial Behavior (RC4) and Aberrant Experiences (RC8) scale scores were significantly elevated for the low-risk group, whereas Somatic Complaints (RC1) scores were elevated for the moderate-risk group, and Somatic Complaints (RC1), Low Positive Emotions (RC2), Antisocial Behavior (RC4), and Ideas of Persecution (RC6) scale scores were elevated for the highrisk group.

Conclusions: Compared to the healthy control group, all three suicide risk groups showed elevated scores on the RC Scales overall, suggesting that various psychopathological factors are involved in the etiology of suicide. More psychopathologic factors were found to influence suicide-related issues in the higher risk groups than lower risk groups, suggesting that more risk factors are involved in higher suicide risk groups. Compared to healthy controls, even the low-risk group showed a significant elevation in emotional factors and antisocial behaviors. While the healthy controls and those at risk of suicide differed significantly on both the Demoralization (RCd) and Negative Emotions (RC7) scales, only the Demoralization (RCd) scale appeared to be able to screen for high suicide risk.

Keywords: Minnesota multiphasic personality inventor-2 restructured form, Suicide, Risk factors

\footnotetext{
*Correspondence: countin@gmail.com

'Department of Psychiatry, Hanyang University Medical Center, 222-1,

Wangsimni-ro, Seongdong-gu, Seoul 04763, Republic of Korea

Full list of author information is available at the end of the article
}

(c) The Author(s). 2020 Open Access This article is distributed under the terms of the Creative Commons Attribution 4.0 International License (http://creativecommons.org/licenses/by/4.0/), which permits unrestricted use, distribution, and reproduction in any medium, provided you give appropriate credit to the original author(s) and the source, provide a link to the Creative Commons license, and indicate if changes were made. The Creative Commons Public Domain Dedication waiver (http://creativecommons.org/publicdomain/zero/1.0/) applies to the data made available in this article, unless otherwise stated. 


\section{Background}

According to health statistics released by the Organization for Economic Co-operation and Development (OECD) in 2018, Korea ranked second with 53.0 suicides per 100,000 people in 2017, and according to the OECD age-adjusted suicide rate, Korea again ranked second with 23.0 suicides (per 100,000 of the OECD standard population) [1]. Because of national policies and interventions to reduce the rate of suicide, which is a serious cause of death in Korea, the number of suicides decreased by $4.8 \%$ in 2017 when compared with the number in 2016. However, the suicide rate for those under the age of 15 years increased by $66.7 \%$ in the same year, and suicide has remained the top cause of death among teenagers and those in their 20s and 30s. Unfortunately, the suicide mortality rate in Korea, which had been declining steadily over the past few years, increased by 2.3 suicides (9.5\%) in 2018 when compared with the value in 2017. Compared with the OECD average age-adjusted suicide rate of 11.5, Korea recorded a higher rate of 24.7, ranking at the top among OECD countries. In particular, the suicide rate increased in individuals of all ages, except those aged 80 years or older, and it was high in teenagers $(22.1 \%)$ and those in their 40s (13.1\%) and 30s (12.2\%) [1]. Considering that a history of suicidal ideation and/or suicidal attempt is the biggest risk factor for suicide, youth with a history of suicidal behavior present a high-risk group with potential for suicide [2]. Importantly, a survey conducted by the American College Health Association in 2015 found that $1.5 \%$ of students reported at least one suicide attempt, and $9.8 \%$ of the students considered suicide seriously at least once during the past year. In Korea, $4.1 \%$ of those aged 19 or older reported having seriously considered dying by suicide [2]. Over the past 50 years, suicide has increased in those aged between 15 and 24 years old, with over 1000 suicides annually. Suicide was the second most common cause of death for the population during this time. Therefore, identifying suicide risk factors for early adults is of particular importance [1].

Suicide risk assessment is challenging; it is particularly difficult to accurately predict the probability of suicide attempt and death by suicide [3]. Understanding suicide risk requires comprehensive evaluation of an individual's intrapersonal and interpersonal characteristics. The key intrapersonal characteristics include clinical diagnoses, such as depression, anxiety, personality disorders, and substance abuse [4]. Suicide is influenced by a wide range of psychopathologies, and in over $90 \%$ of those who commit suicide, a complex interaction of psychiatric disorders, including mood disorders, substance abuse disorders, anxiety disorders, and personality disorders, precedes suicide $[5,6]$. Therefore, it is crucial to grasp the characteristics of various types of psychopathologies. Minnesota Multiphasic Personality Inventory2 (MMPI-2) is widely used in suicide risk research to assess the emotional state and personality of patients in clinical settings [7-9]. However, studies conducted with the MMPI-2 Clinical Scales have yielded inconsistent findings, including the relationships between suicidal ideation and behavior and elevations of Scales 3 (Hysteria), 4 (Psychopathic Deviate), 7 (Psychasthenia), 9 (Hypomania), and 0 (Social Introversion) in addition to Scales 2 (Depression), 6 (Paranoia), and 8 (Schizophrenia) [9-13]. Also in Korean studies analyzing MMPI-2 results of patients with major depression, only the 6 (Paranoia) clinical scale was shown as 'high' in those with a suicidal attempt history as compared to those without such history [14]. Seo et al. reported that the MMPI-2 clinical scales 6 (Paranoia), 8 (Schizophrenia), and 9 (Hypomania) were noted as significantly high in 75 patients who attempted suicide as compared to 115 people in the control group [15].

The poor discriminatory power of the MMPI-2 scales in suicide risk assessment is due to the high correlations among the MMPI-2 Clinical Scales [16]. Notably, the demoralization factor is scattered around Clinical Scales and elevates multiple scales together, making it difficult to interpret profiles accurately. Therefore, the demoralization factor was removed from the scales to measure the original key elements, and the "restructured" Clinical Scales became the Restructured Clinical (RC) Scales of the MMPI-2-RF [16, 17]. The Restructured Clinical Scales shows improved convergent validity and discriminant validity to the existing clinical scale. We confirmed that the revised clinical scale aids greatly in resolution of analytical ambiguity questions that are raised regarding the clinical scales. And the RC scales of the MMPI-2-RF can likely indicate an individual's overall intrapersonal characteristics and increase the likelihood of diagnosing pathologies [16, $18,19]$. Which are required to evaluate the suicide risk because they describe the individual's overall functional level according to the center points of all measurements, in addition to the three higher-order $(\mathrm{H}-\mathrm{O})$ scales of the measure [20].

Among MMPI-2-RF scales, RC scales have been found to have higher internal consistency and lower interrelationship when compared with clinical scales, and evidence regarding their validity is accumulating from empirical studies conducted in various settings, such as mental health outpatient clinics and wards, individual counseling settings, university counseling centers, drug addiction treatment centers, and correctional facilities $[16,21-27]$. Some previous studies suggested that MMPI-2-RF could be used to assess suicide risk [28, 29]. The previous study on psychiatric outpatients reported that the interaction of $\mathrm{RCd}$ and $\mathrm{RC} 9$ differed between patients with suicide attempts and patients with no attempts, but both groups had suicidal ideation. It also reported that the high score of RCd and RC9 had a static 
correlation with suicide attempt [30].. Another on the usefulness of RF scales demonstrated that the Emotional/Intenalizing Dysfunction (EID), Behavioral/Externalizing Dysfunction (BXD), Low Positive Emotions (RC2), hypomanic activation (RC9), Helplessness/Hopelessness (HLP), Anxiety (AXY), and Suicidal/Death Ideation (SUI) scales had significant explanatory power for suicide risk [8]. In addition, the SUI, RCd and RC2 scales showed a significant correlation with the history of suicidal attempts, the history of suicidal ideation, recent suicidal ideation, and suicide risk information from patient interviews which included details for suicide attempts in the last month [31].

\section{Objectives}

In this research, we investigated the possibility of screening for suicide risk using the MMPI while reflecting the limitations of repeated investigations in the literature on suicidal risk and the MMPI-2-RF, suicidal tendency and classification of risk groups using suicidality module of MINI.

Suicidal ideation is used to predict suicide risk because it is considered to be on spectrum continuum associated with suicide attempt and suicide, and in particular, individuals with high suicidal ideation might have multiple suicide attempts [32, 33].

We identified the pathological personality types that have the greatest effect on suicidal risk groups among the MMPI-2-RF RC total scale to compensate for the drawbacks described in prior research which showed the relationship between suicidal risk utilizing only the $\mathrm{RCd}$ and RC9 scales (emotional pain indicators based on depression/hopelessness), and furthermore to identify cutoff values for the psychological levels of intrapersonal characteristics using Receiver Operating Characteristic (ROC) curve analysis.

\section{Methods}

\section{Study participants}

This study used the data from the Capacity Building Project conducted in Kongju National University. All participants were students, the confidentiality of the results explained and the use of their survey responses for research, and they provided written consent. The study analyzed the answers given by 7824 students out of a total of 8769, excluding 945 students (3685 men and 4139 women) were included in the data analyses. The study was approved by the institutional review board of Kongju National University.

\section{Measures}

Minnesota multiphasic personality inventory-2-restructured form (MMPI-2-RF)

To confirm the psychological characteristics associated with suicide risk, we used the Minnesota Multiphasic
Personality Inventory-2-Restructured Form (MMPI-2$\mathrm{RF}$ ) released in 2011. The measure involves a questionnaire with a total of 338 items, each of which is answered "Yes" or "No," and there are a total of 50 scales to effectively measure the clinical meaning of MMPI-2 items. The 50 scales of MMPI-2-RF have a hierarchical structure, and they were developed to minimize conceptual redundancy among the scales. They include eight validity scales, 42 main scales (three $\mathrm{H}-\mathrm{O}$ scales, nine $\mathrm{RC}$ scales, 23 specific problem scales, two interest scales, and PSY-5 [personality psychopathology five] scales). This study focused on the nine RC scales [RCd (Demoralization), RC1(Somatic Complaints), RC2(Low Positive Emotions), RC3(Cynicism), RC4(Antisocial Behavior), RC6(Ideas of Persecution), RC7(Dysfunctional Negative Emotions), RC8(Aberrant Experiences), RC9(Hypomanic Activation)] for analysis. We used the Korean version of the MMPI-2RF [18].

\section{Suicide risk assessment}

Suicide risk was assessed using the suicide risk assessment module of the Korean version of the Mini International Neuropsychiatric Interview (MINI). The MINI is a structured interview tool developed in 1998 for the diagnosis of Axis I disorders of DSM-IV and ICD-10. It has verified a minimum 0.70 specificity and a 0.85 sensitivity in MINI in clinical interview situations such as the Structured Clinical Interview for the DSM, throughout named psychological disorders [34].

In this study, the Korean version 5.0.0 was used, which was standardized [35]. Among these, suicidal tendency was assessed using the suicidal tendency module developed by Sheehan et al., which includes the following six questions related to "wish for death" with varying weights [36]. We followed 307 patients discharged from the psychiatric ward for 1 year. We analyzed the results using the MINI scale to find a potential predictor of suicide attempt. The subjects were categorized in four groups (no symptoms, suicidal behavior, suicidal behavior and NSSI, and NSSI only) including a group with suicidal behavior and a non-suicidal self-harm group (NSSI). The total score of the MINI showed a significant correlation to the self-harm group when stratified by age, sex and psychiatric diagnosis. We divided the patients into a moderate-risk group and a high-risk group using the MINI score 6 (or more than two positive items) and score 10 (or more than three positive items) as criteria. These criteria showed good sensitivity (0.61$0.75)$ and specificity $(0.61-0.75)$ established from the patient history of self-harm acts. When each group was considered, the MINI suicidal sub-scale score was a good predictor in two groups with suicidal behavior, but not in the NSSI group [37]. 
Current suicidal risk is assessed using six items. A response of "Yes" to at least one of the six items is considered as being at risk of suicide. Based on the sum of the weighted scores of the "Yes" items, 1-5 points are classified as low-risk, 6-9 points as moderate-risk, and 10 points and higher as high-risk. In this study, the low-, moderate-, and high-risk groups were compared with one another and with the controls, whose total suicide risk scores were 0 .

\section{The Korean version of the patient health questionnaire-9 (PHQ-9)}

This depression screening tool is a self-report questionnaire $[38,39]$. The instrument includes nine items that correspond to the nine DSM-IV diagnostic criteria for major depressive episode. Each item is scored 0-3, and the total score ranges between 0 and 27. In this study, the Korean version of the PHQ-9 with established reliability and validity since its adaptation into Korean in 2010 was used [40]. Cronbach's alpha in this study was 0.822 .

\section{Statistical analysis}

Demographic variables were analyzed using t-tests and $\mathrm{X}^{2}$ tests. The differences between the three suicide risk groups on the MMPI-2-RF RC Scales were tested using analysis of variance (ANOVA). To lower the probability of type 1 error, we tested significance with a $p$-value $<.01$ and used Scheffés method as a post-hoc test. The relationships between the RC Scales and the different suicide risk groups were tested using multiple logistic regression. We performed a multinomial logistic regression analysis instead of individual logistic regression analyses, and we categorized and compared the suicide risk groups according to low, medium, and high risk. Furthermore, the reference group of the multinomial logistic regression analysis was set as the control group and was compared with the other groups according to the suicide risk level. To determine how well the Demoralization (RCd) and Negative Emotions (RC7) scales, which showed the largest differences for those at risk of suicide, discriminated between the suicide risk groups, receiver operating characteristics (ROC) curve analysis (MedClac version 18.10.2) was performed and the sensitivity and specificity of individual cutoff scores were examined. Statistical analysis was performed using the SPSS 24.0 (IBM corp., Armonk, NY, USA).

\section{Results}

\section{Demographic characteristics}

Out of the 7824 participants (age range: 17 48), 964 (12.3\%) were endorsed at least one of the suicide risk items on the MINI. The mean age of the suicide risk group was 19.61 years $(\mathrm{SD}=1.1)$ and the group included
$613(63.6 \%)$ female students. While the group's mean age was not significantly different from that of controls, the female ratio was higher than in the control group (51.4\%, $N=3526)$. The 964 subjects at risk of suicide were classified into the low-risk group (57.4\%), moderate-risk group (32.4\%), and high-risk group (10.3\%) (Table 1).

\section{Analysis of MMPI-2-RF RC scales by suicide risk group}

The MMPI-2-RF scores of the low-risk group, the moderate-risk group, and the high-risk group were analyzed to determine potential differences between the groups.

The three groups' scores were significantly elevated on all nine RC Scales $(p<0.001)$, but most elevated on the Demoralization (RCd) and Emotions (RC7) scales. The $\mathrm{RC}$ Scale scores were higher in the groups with higher suicide risk.

The Demoralization (RCd), Somatic Complaints (RC1), Low Positive Emotions (RC2), Cynicism (RC3), and Negative Emotions (RC7) scale scores were significantly higher in the moderate-risk group than the low-risk group; all the RC Scale scores except Hypomanic Activation (RC9) were significantly higher in the high-risk group than the low-risk group $(p<0.001)$; the Somatic Complaints (RC1), Low Positive Emotions (RC2), Cynicism (RC3), Antisocial Behavior (RC4), and Ideas of Persecution (RC6) scale scores were significantly higher in the high-risk group than in the moderate-risk group (Table 2, Fig. 1).

\section{Regression analysis for suicide risk and MMPI-2-RF scale scores}

Table 3 shows the results of effects of the suicide risk groups on the RC Scale scores adjusted based on the control group. Odds ratios (ORs) for the Demoralization (RCd) across all three groups were significant: 1.067 (95\% CI 1.054-1.080) for the low-risk group, 1.088 (95\% CI 1.072-1.105) for the moderate-risk group. The odds ratio was 1.085 (95\% CI 1.057-1.114) for the high suicide risk group, which indicates greater risk when compared with that for the control group. At the $P$ value of 0.001 , the most significant ORs were 1.061 (RC1, 95\% CI 10.37-1.085) in the high-risk group and 1.030 (RC4, 95\% CI 1.017-1.042) in the low-risk group.

\section{Diagnostic power of demoralization ( $\mathrm{RCd}$ ) and negative emotions (RC7) for suicide risk groups}

Among the RC scales, Demoralization (RCd) and Dysfunctional Negative Emotions (RC7) showed the largest significant difference between the control group and three suicide risk groups, and we conducted ROC analysis to determine how accurately the two scales discriminate the groups with regard to suicide risk. For the Demoralization (RCd), the area under the curve (AUC) 
Table 1 General characteristics of the participants $(n=7824)$

\begin{tabular}{|c|c|c|c|c|}
\hline & Suicidal risk group $(n=964)$ & Control $(n=6860)$ & t or $x^{2}$ & $P$-value \\
\hline Age & $19.61 \pm 1.1$ & $19.57 \pm 1.3$ & 0.854 & 0.393 \\
\hline Sex & & & 50.407 & $<0.001$ \\
\hline Male & $351(36.4 \%)$ & $3334(48.6 \%)$ & & \\
\hline Female & $613(63.6 \%)$ & $3526(51.4 \%)$ & & \\
\hline PHQ-9 score & $8.46 \pm 5.2$ & $3.9 \pm 3.4$ & 36.517 & $<0.001$ \\
\hline \multicolumn{5}{|l|}{ Suicide risk } \\
\hline Low & $553(57.4 \%)$ & & & \\
\hline Medium & $312(32.4 \%)$ & & & \\
\hline High & $99(10.3 \%)$ & & & \\
\hline
\end{tabular}

of the ROC, which indicates diagnostic accuracy, was highest at $81.9 \%(p<0.001)$ for the high-risk group, indicating a moderate accuracy level, followed by $78.9 \%$ for the moderate-risk group and $71.1 \%$ for the low-risk group. For Negative Emotions (RC7), the AUC was $75.5 \%$ for the high-risk group, $74.1 \%$ for the moderaterisk group, and $67.3 \%$ for the low-risk group, suggesting moderate predictive power of Negative Emotions (RC7) as well (Table 4). For the Demoralization (RCd) of the highrisk group with the highest predictive accuracy, the cutoff score was 52, and sensitivity and specificity were 71.7 and 77.4\%, respectively (Fig. 2). AUC scores were lower for Negative Emotions (RC7) than for Demoralization (RCd), indicating fair accuracy; however, the Negative Emotions (RC7) cutoff score for the high suicide risk group was 55, and the sensitivity and specificity of the scale were 64.7 and $78.4 \%$, respectively.

\section{Discussion}

This study investigated the utility of the MMPI-2-RF as a suicide risk assessment tool and the variation in the RC Scales according to suicide risk.

The RC Scales varied in score elevation according to suicide risk level. For all three suicide risk groups, the $\mathrm{RC}$ Scale scores were significantly higher than in the

Table 2 Summary of descriptive statistics for MMPI-2-RF restructured clinical (RC) scales among suicidal risk groups

\begin{tabular}{|c|c|c|c|c|c|c|c|c|c|c|c|c|}
\hline & $\begin{array}{l}\text { Control }(n= \\
6860)\end{array}$ & $\begin{array}{l}\text { Suicidal Low risk } \\
(n=553)\end{array}$ & $\begin{array}{l}\text { Suicidal Moderate } \\
\text { risk }(n=312)\end{array}$ & $\begin{array}{l}\text { Suicidal High risk } \\
(n=99)\end{array}$ & $F$ & $P$ & d1 & $d 2$ & d3 & $\mathrm{d} 4$ & d5 & $\mathrm{d} 6$ \\
\hline $\mathrm{RCd}$ & $45.22 \pm 10.200$ & $55.22 \pm 12.763$ & $60.04 \pm 13.479$ & $62.95 \pm 13.875$ & 405.747 & $\begin{array}{l}< \\
0.001\end{array}$ & $10.002^{b}$ & $14.816^{b}$ & $17.727^{b}$ & $4.814^{b}$ & $7.725^{b}$ & 2.911 \\
\hline $\mathrm{RC} 1$ & $45.59 \pm 7.582$ & $49.87 \pm 9.309$ & $51.80 \pm 10.469$ & $57.36 \pm 13.144$ & 169.700 & $\begin{array}{l}< \\
0.001\end{array}$ & $4.282^{b}$ & $6.219^{b}$ & $11.778^{b}$ & $1.936^{\mathrm{a}}$ & $7.496^{b}$ & $5.559^{b}$ \\
\hline $\mathrm{RC2}$ & $45.44 \pm 8.140$ & $47.67 \pm 9.613$ & $50.07 \pm 11.058$ & $53.63 \pm 12.744$ & 67.657 & $\begin{array}{l}< \\
0.001\end{array}$ & $2.230^{b}$ & $4.630^{b}$ & $8.189^{b}$ & $2.400^{b}$ & $5.959^{b}$ & $3.559^{a}$ \\
\hline $\mathrm{RC} 3$ & $42.20 \pm 7.255$ & $45.66 \pm 8.338$ & $47.39 \pm 9.396$ & $49.94 \pm 11.829$ & 110.107 & $\begin{array}{l}< \\
0.001\end{array}$ & $3.464^{b}$ & $5.192^{b}$ & $7.740^{b}$ & $1.727^{\mathrm{a}}$ & $4.276^{b}$ & $2.548^{a}$ \\
\hline $\mathrm{RC} 4$ & $44.24 \pm 8.000$ & $49.21 \pm 9.370$ & $48.98 \pm 8.288$ & $53.03 \pm 10.223$ & 125.715 & $\begin{array}{l}< \\
0.001\end{array}$ & $4.967^{b}$ & $4.742^{b}$ & $8.794^{b}$ & 0.234 & $3.189^{b}$ & $4.053^{b}$ \\
\hline $\mathrm{RC} 6$ & $44.20 \pm 8.185$ & $49.08 \pm 9.938$ & $49.76 \pm 9.991$ & $56.17 \pm 12.547$ & 152.973 & $\begin{array}{l}< \\
0.001\end{array}$ & $4.872^{b}$ & $5.552^{b}$ & $11.967^{b}$ & 0.680 & $7.096^{b}$ & $6.415^{b}$ \\
\hline $\mathrm{RC7}$ & $48.51 \pm 9.409$ & $55.66 \pm 11.155$ & $58.69 \pm 11.295$ & $60.52 \pm 12.584$ & 235.133 & $\begin{array}{l}< \\
0.001\end{array}$ & $7.143^{b}$ & $10.176^{b}$ & $12.002^{b}$ & $3.033^{b}$ & $4.859^{b}$ & 1.826 \\
\hline $\mathrm{RC} 8$ & $46.64 \pm 8.224$ & $52.37 \pm 9.930$ & $53.28 \pm 11.133$ & $55.96 \pm 12.783$ & 162.141 & $\begin{array}{l}< \\
0.001\end{array}$ & $5.726^{\mathrm{b}}$ & $6.641^{b}$ & $9.319^{b}$ & 0.915 & $3.593^{b}$ & 2.678 \\
\hline $\mathrm{RC} 9$ & $47.46 \pm 8.417$ & $51.44 \pm 9.457$ & $51.74 \pm 9.003$ & $52.95 \pm 11.605$ & 69.810 & $\begin{array}{l}< \\
0.001\end{array}$ & $3.985^{b}$ & $4.286^{b}$ & $5.491^{b}$ & 0.301 & 1.506 & 1.206 \\
\hline
\end{tabular}

${ }^{\mathrm{a}} P<0.01$

${ }^{\mathrm{b}} P<0.05$

Scheffé ANOVA post hoc test was used. MMPI-2-RF Minnesota multiphasic personality inventory-2-restructured form, $R C d$ Demoralization, $R C 1$ Somatic complaints, $R C 2$ Low positive emotions, $R C 3$ Cynicism, $R C 4$ Antisocial behavior, $R C 6$ Ideas of persecution, $R C 7$ Dysfunctional negative emotions, $R C 8$ Aberrant experiences, $R C 9$ Hypomanic activation, $d 1$ Control vs suicidal low risk group, $d 2$ Control versus suicidal moderate risk group, $d 3$ Control versus suicidal high risk group, $d 4$ Suicidal low risk group versus suicidal moderate risk group, $d 5$ Suicidal low risk group versus suicidal high risk group, $d 6$ Suicidal moderate risk group versus suicidal high risk group 


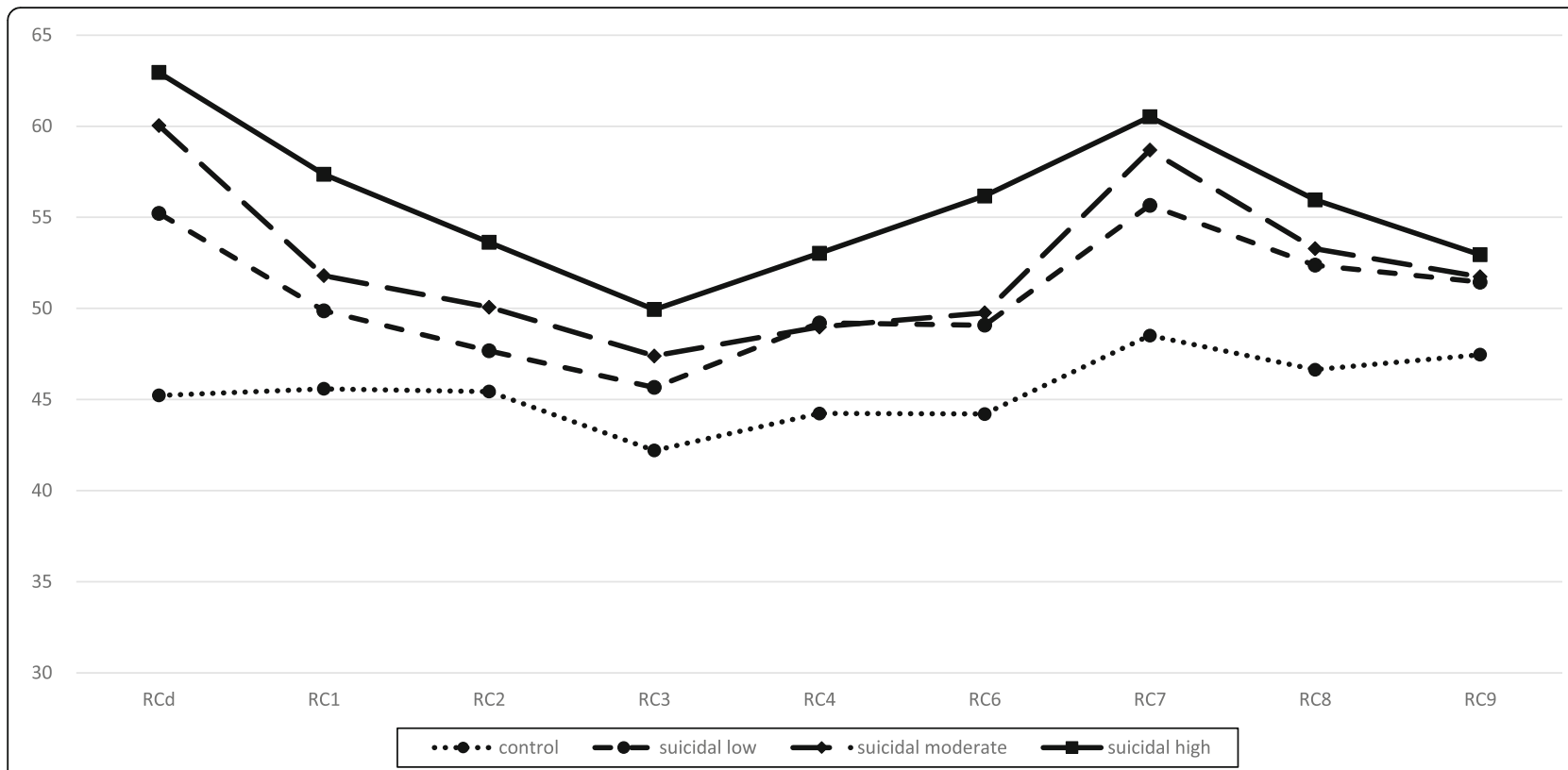

Fig. 1 The profiles of the MMPI-2-RF restructured clinical (RC) scales among the 3 suicidal risk groups and control group

control group. This suggests that various psychopathological characteristics are involved in suicide, and is consistent with previous findings [13]. In particular, the Demoralization (RCd) and Dysfunctional Negative Emotions (RC7) Scale scores varied according to suicide risk level as well as between controls and those at risk of suicide. In all three suicide risk groups, the Demoralization (RCd) scores were highest, followed by the Dysfunctional Negative Emotions (RC7) scores. For both Demoralization (RCd) and Dysfunctional Negative Emotions (RC7), the difference between the three groups was significant, but the difference between the moderate- and the high-risk groups was not. This result can be interpreted as reflecting the characteristics of the MINI which was used for suicide risk assessment. In the MINI, those who planned, attempted, or considered suicide within a month are classified into the moderate- and the high-risk groups.

The Demoralization (RCd) and Dysfunctional Negative Emotions (RC7) may only be able to discriminate the low-risk group from higher risk groups. Regarding the Demoralization (RCd), high scale scores indicate demoralization, which is manifested by dissatisfaction and unhappiness in life as a whole, a sense of helplessness and inefficiency, and a pessimistic attitude toward the future. Elevation in Demoralization ( $\mathrm{RCd})$ is often accompanied by "patienthood," including hopelessness, pessimism, self-degradation, depression, suicidal ideation, and somatic complaints [12]. The Dysfunctional

Table 3 The association between MMPI-2-RF restructured clinical (RC) scales and suicidal risk group (the result of multiple logistic regression analysis)

\begin{tabular}{|c|c|c|c|c|c|c|}
\hline & \multicolumn{2}{|c|}{ Suicidal Low risk group } & \multicolumn{2}{|c|}{ Suicidal Moderate risk group } & \multicolumn{2}{|c|}{ Suicidal High risk group } \\
\hline & OR $(96 \% \mathrm{Cl})$ & $p$ value & OR $(96 \% \mathrm{Cl})$ & $p$ value & OR $(96 \% \mathrm{Cl})$ & $p$ value \\
\hline$\overline{\mathrm{RCd}}$ & $1.067(1.054-1.080)$ & $<0.001^{*}$ & $1.088(1.072-1.105)$ & $<0.001^{*}$ & $1.085(1.057-1.114)$ & $<0.001^{*}$ \\
\hline $\mathrm{RC} 1$ & 1.008(0.995-1.020) & 0.224 & $1.021(1.005-1.036)$ & $0.007^{*}$ & $1.061(1.037-1.085)$ & $<0.001^{*}$ \\
\hline $\mathrm{RC2}$ & 0.996(0.983-1.009) & 0.573 & $1.007(0.991-1.024)$ & 0.377 & $1.030(1.005-1.056)$ & $0.017^{*}$ \\
\hline $\mathrm{RC} 3$ & 0.990(0.976-1.004) & 0.165 & $1.007(0.990-1.024)$ & 0.422 & $1.006(0.979-1.034)$ & 0.654 \\
\hline RC4 & $1.030(1.017-1.042)$ & $<0.001^{*}$ & $1.016(1.000-1.032)$ & 0.057 & $1.029(1.004-1.055)$ & $0.023^{*}$ \\
\hline $\mathrm{RC6}$ & 0.996(0.983-1.009) & 0.537 & $0.984(0.968-1.001)$ & 0.065 & $1.031(1.005-1.056)$ & $0.017^{*}$ \\
\hline $\mathrm{RC7}$ & 0.994(0.979-1.009) & 0.430 & $1.000(0.981-1.019)$ & 0.983 & $0.977(0.946-1.009)$ & 0.152 \\
\hline $\mathrm{RC} 8$ & $1.015(1.002-1.029)$ & $0.028^{*}$ & $1.008(0.990-1.025)$ & 0.391 & $0.984(0.957-1.012)$ & 0.250 \\
\hline RC9 & $1.006(0.991-1.020)$ & 0.459 & $1.007(0.987-1.026)$ & 0.505 & $1.015(0.983-1.049)$ & 0.350 \\
\hline
\end{tabular}

OR Odds ratio, $C /$ Confidence interval, $R C d$ Demoralization, $R C 1$ Somatic complaints, $R C 2$ Low positive emotions, $R C 3$ Cynicism, $R C 4$ Antisocial behavior, $R C 6$ Ideas of persecution, $R C 7$ Dysfunctional negative emotions, $R C 8$ Aberrant experiences, $R C 9$ Hypomanic activation

*: statistically significant 
Table 4 The sensitivity and specificity for different cutoff points of between suicidal risk group and RCd, RC7

\begin{tabular}{|c|c|c|c|c|c|}
\hline & Cut off & AUC & Sensitivity & Specificity & $P$ value \\
\hline \multicolumn{6}{|c|}{ Suicidal Low risk } \\
\hline $\mathrm{RCd}$ & 45 & $0.711(0.701-0.721)$ & 73.06(69.2-76.7) & $57.35(56.2-58.5)$ & $<0.0001$ \\
\hline RC7 & 49 & $0.673(0.663-0.684)$ & $67.81(63.7-71.7)$ & $58.70(57.6-59.8)$ & $<0.0001$ \\
\hline \multicolumn{6}{|c|}{ Suicidal Moderate risk } \\
\hline $\mathrm{RCd}$ & 49 & $0.789(0.780-0.798)$ & $74.68(69.5-79.4)$ & $68.86(67.8-69.9)$ & $<0.0001$ \\
\hline RC7 & 51 & $0.741(0.731-0.751)$ & 70.83(65.4-75.8) & $66.07(65.0-67.1)$ & $<0.0001$ \\
\hline \multicolumn{6}{|c|}{ Suicidal High risk } \\
\hline $\mathrm{RCd}$ & 52 & $0.819(0.811-0.828)$ & $71.72(61.8-80.3)$ & $77.36(76.4-78.3)$ & $<0.0001$ \\
\hline RC7 & 55 & $0.755(0.746-0.765)$ & $64.65(54.4-74.0)$ & 78.38(77.4-79.3) & $<0.0001$ \\
\hline
\end{tabular}

Negative Emotions (RC7) indicates dysfunctional Negative Emotions, including anxiety, anger, and fear. Those with high Dysfunctional Negative Emotions (RC7) scores are likely to develop an anxiety disorder, and experience excessive rumination and a sense of guilt [10]. The Demoralization (RCd) and Negative Emotions (RC7) scores indicate issues originating from emotional problems; therefore, emotional pain can be considered a major factor that distinguishes between normal and suicidal groups, The psychiatric theory of Shneidman (1993) and the interpersonal-psychological theory by Joiner (2005) state that suicidal behavior results from psychological pain caused by frustrated need [41, 42]. The escape theory of Baumeister (1990) maintains that psychological pain is derived from negative effects generated by aversive self-awareness [43]. Each theory suggests a different cause for psychological pain but the theories agree that the desire of suicide stems from psychological pain [44]. Moreover, the "ideation-to-action" theory of Klonsky and May (2014) expresses that suicidal ideations grow and progress to strong ideations when the amount of pain is greater than that of connectedness to others, and the ideation proceeds to an attempt depending on the possibility of a suicide attempt [45]. Therefore, the group with a high risk of suicide would have a high level of a combination of pain and hopelessness. Therefore, this emotional pain can be presented by $\mathrm{RCd}$ and RC7.

Moreover, the odds ratios for the two scales increased with the suicide risk indicated by the group membership, suggesting that the effect of mental pain on suicide increases as the degree of mental pain increases. The results also indicate the scales' discriminatory power in distinguishing between those at risk and controls.

The high-risk suicide group scored higher than the low-risk group on all RC Scales except RC9, and was influenced by more RC Scales compared to the low/ moderate risk groups, suggesting the presence of more psychopathological personality factors. The findings suggest that a higher suicide risk level is associated with the presence of various psychopathic personality factors that increase suicide risk [11]. However, the difference
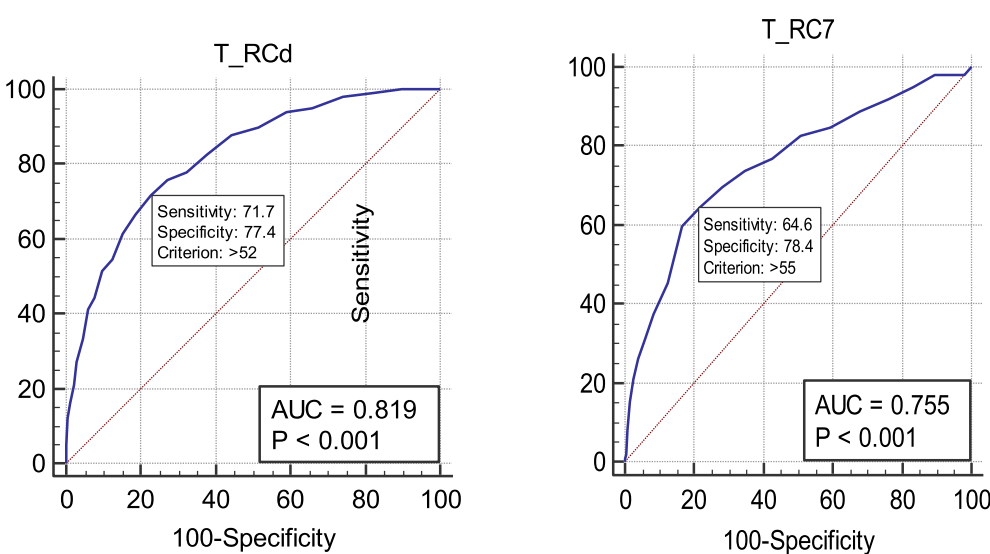

Fig. 2 ROC curve of the Demoralization (RCd) in suicidal high suicidality group. AUC $=0.819$ ( $95 \%$ Cl 0.811 to 0.828 ), ROC: Receiver Operating Characteristics, AUC: Area Under the Curve 
between the moderate- and the high-risk groups was large for the Demoralization (RC1), Low Positive Emotions (RC2), Cynicism (RC3), Antisocial Behavior (RC4), and Ideas of Persecution (RC6) scales, and Somatic Complaint (RC1), Low Positive Emotions (RC2), Antisocial Behavior (RC4), and Ideas of Persecution (RC6) were significant in the regression analysis, suggesting that the Demoralization ( $\mathrm{RCd}$ ) and the four RC scales reflect significant psychopathological issues for the high-risk suicide group. The Somatic Complaint (RC1), Low Positive Emotions (RC2), Antisocial Behavior (RC4), and Ideas of Persecution (RC6) Scales suggest that suicide planning and suicide attempt in the high-risk suicide group is a combined effect of emotional, behavioral, and cognitive characteristics.

The moderate-risk group differed significantly from the low/high-risk groups on the $\mathrm{RCd}$ and $\mathrm{RC} 1$. The low-risk group showed an overall elevation in the RC Scales compared to the control group and was significantly influenced by the Demoralization (RCd), Antisocial Behavior (RC4), and Aberrant Experiences (RC8) scores. This suggests that even the low-risk group may have distinct behaviors and perceptual experiences such as antisocial behaviors (RC4). Along with the unusual thinking and perceptual experience of Aberrant Experiences (RC8), the common traits of the both scales (easily changing emotions) can be considered a characteristic that predicts suicide.

The significantly high Demoralization (RCd) and Negative Emotions ( $\mathrm{RC7}$ ) scores and ORs demonstrate that they are important psychopathological predictors of suicide. Although the Demoralization (RCd) and Negative Emotions (RC7) scores are highly correlated, their content and experiential correlates are distinct; therefore, distinct emotional and experiential factors are likely involved in the etiology of suicide [9].

According to the results of the ROC curve analysis designed to determine the diagnostic accuracy of the Demoralization (RCd) and Negative Emotions (RC7) scales for suicide risk, the AUCs for both Demoralization (RCd) and Negative Emotions (RC7) varied according to suicide risk. The AUCs for the Demoralization (RCd) were highest for the high-risk group, followed by the moderate-risk group (0.789) and the low-risk group (0.711). Similarly, the AUCs for the Negative Emotions (RC7) were highest for the high-risk group (0.755), followed by the moderate-risk group (0.741) and the low-risk group (0.673). The results suggest an overall moderate accuracy level except for Negative Emotions (RC7) in the low-risk group [16]. The Demoralization (RCd) had the largest AUC, classifying 77\% of the highrisk group. In this study, the scale that was most effective in discriminating between the high- and the moderate-risk for suicide groups was the Demoralization (RCd) followed by Negative Emotions (RC7) [17].
The findings of this study have significant implications for suicide risk assessment, as we segmented the suiciderisk group in a sample of college students in a nonclinical setting, and analyzed the psychopathological factors that affect suicide risk using the widely used MMPI2-RF RC Scales in suicide risk assessment.

This study has some limitations. First, study participants were a non-clinical sample of college students. Patients with mental illness are 3 to 12 times more likely to commit suicide when compared with other patients. Individuals with depression are more likely to experience suicidal death than the general population, and among psychiatric patients, those with suicidal ideation along with substance abuse and impulse control disorder have a high risk of attempting suicide. Accordingly, the clinical population is expected to manifest more diverse and complex psychopathological personality characteristics when compared with the non-clinical population, suggesting the need for further research involving a clinical population. Further research is needed with clinical populations.

Second, all study data were obtained from self-report tests, limiting the reliability of responses.

The suicide risks and pathological characteristics of individuals should be assessed using various tools and methods, such as direct and indirect measures designed to determine suicide tendencies, assessment methods used by clinicians, and psychological tests, to identify individual psychopathological personality characteristics.

Third, detailed data on suicide are needed. The purpose of this study was to evaluate the risk of suicide using a module of the MINI, but no detailed information about the criticality of suicide risk, method or frequency was obtained. Therefore, an assessment tool for the accurate segmentation of suicide risk groups based on a greater specificity of suicidal ideation, attempts, and planning is required.

Notwithstanding these limitations, this study has particular significance for segmenting and analyzing suicide risk using the MMPI-2-RF RC Scales. In this study, psychopathological factors affecting suicide were also identified by examining the effects of the RC Scales in discriminating between different levels of suicide risk. In most studies on suicide risk and tendency using the MMPI-2-RF, the authors recognized a correlation with suicide through use of the RC scale (e.g., RCd and RC9) based on an emotional theory or an interaction between the scales. In contrast, we identified the RC scales presenting differential effects on each suicide risk group; only the RC9 had no effect on the high-risk group. Our findings disagree with precedent studies stating that RC9 is the major scale which influences suicide risk. Our research implies that stratification of the risk groups allows for more specific assessments. Furthermore, we found the reference point of RCd and RC7 (the most influential scale for all suicide risk groups) in the non-clinical population by ROC analysis. 


\section{Conclusions}

The study examined the differences between the RC Scales according to suicide risk level. Compared to a healthy control group, all three suicide risk groups' scores were higher on the MMPI-2-RF RC Scales in general, suggesting that various psychopathological characteristics are involved in suicide risk. It was also found that more psychopathological factors, and therefore more risk factors, influenced suicide-related issues in the groups with a higher risk for suicide. Even the low-risk for suicide group differed from the healthy control group for emotional factors and antisocial behaviors. The highrisk suicide group was differed to a large extent from the other groups on the Demoralization (RCd) and Negative Emotions (RC7) scales, suggesting their utility in screening for suicide risk.

\section{Abbreviations}

ANOVA: Analysis of variance; MMPI-2-RF: Minnesota Multiphasic Personality Inventory-2 Restructured Form; OR: Odds ratios; PHQ-9: Patient health questionnaire-9; RC: Restructured Clinical Scales

\section{Acknowledgements}

None.

\section{Authors' contributions}

Conception of the study: KL, HKL, SK. Data collection: HKL, KL. Data analysis: SK, KL. Writing of the first draft: SK, HKL, KL. All authors read and approved the final manuscript.

\section{Funding}

This research was supported by Basic Science Research Program through the National Research Foundation of Korea (NRF) funded by the Ministry of Education (NRF-2018R1D1A1B07050245). The funding sources will not have any role during its execution, analyses, interpretation of the data, or decision to submit results.

\section{Availability of data and materials}

The datasets analyzed during the current study are not publicly available due Personal Information Protection Act of Korea.

\section{Ethics approval and consent to participate}

Informed written consent was obtained from all participants. After providing a complete description of the study, including a statement that the questionnaire results would be used for the purpose of the study while remaining confidential, informed consent was provided by all participants. Approval for this study was obtained from the Institutional Review Board of Kongju National University.

\section{Consent for publication}

Not applicable.

\section{Competing interests}

The authors declare that they have no competing interests.

\section{Author details}

'Department of Psychiatry, Hanyang University Medical Center, 222-1, Wangsimni-ro, Seongdong-gu, Seoul 04763, Republic of Korea. ${ }^{2}$ Department of Nursing, College of Nursing and Health, Kongju National University, 56 Gongjudaehak-ro, Gongju 32588, Republic of Korea.
Received: 18 August 2019 Accepted: 13 February 2020

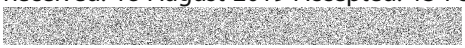

\section{References}

1. Korea National Statistical Office. 2018 Annual report on the cause of death statistics. Korea National Statistical Office. http://kostat.go.kr/portal/eng/ pressReleases/8/10/index.board. Accessed 23 Sept 2019.

2. National Emergency Department Information System Statistics 2018 annual report. http://www.e-gen.or.kr/. Accessed 26 Aug 2019.

3. Nock MK, Borges G, Bromet EJ, Cha CB, Kessler RC, Lee S. Suicide and suicidal behavior. Epidemiol Rev. 2008:30:133-54.

4. Packman WL, Marlitt RE, Bongar B, O'Connor Pennuto T. A comprehensive and concise assessment of suicide risk. Behav Sci Law. 2004;22(5):667-80.

5. Conwell Y, Duberstein PR, Cox C, Herrmann JH, Forbes NT, Caine ED. Relationships of age and axis I diagnoses in victims of completed suicide: a psychological autopsy study. Am J Psychiatry. 1996;153(8):1001-8.

6. Lee K, Lee HK, Kim SH. Temperament and character profile of college students who have suicidal ideas or have attempted suicide. J Affect Disord. 2017;221:198-204.

7. Han K, Lim J, Min B, Lee J, Moon K, Kim Z. Korean MMPI-2 standardization study. J Korean J Clin Psychol. 2006;25(2):533-64.

8. Moon K, Lee J-Y, Heo J. Psychological characteristics of college students with suicide risk in MMPI-2-RF. Korean J Clin Psychol. 2015;34(3):809-27.

9. Lee K, Lee HK, Kim SH, Jang E-Y, Kim D. Suicide risk and the MMPI-2 findings among college students. J Anxiety Mood. 2015;11:120-8.

10. Kopper BA, Osman A, Osman JR, Hoffman J. Clinical utility of the MMPI-A content scales and Harris-Lingoes subscales in the assessment of suicidal risk factors in psychiatric adolescents. J Clin Psychol. 1998;54(2):191-200.

11. Sepaher I, Bongar B, Greene RL. Codetype base rates for the "I mean business" suicide items on the MMPI-2. J Clin Psychol. 1999;55(9):1167-73.

12. Kopper BA, Osman A, Barrios FX. Assessment of suicidal ideation in young men and women: the incremental validity of the MMPI-2 content scales. Death Stud. 2001;25(7):593-607.

13. Lee JY, Moon KJ, Heo JY. The relationship between suicidal ideation and MMPI-2 profile among college students. J Hum Underst Couns. 2012;33(2):53-69.

14. Lee SA, Kim KH, Suh SY. Comparison of emotional and psychological characteristics between suicide attempters and non-attempters in depressed patients: using MMPI-2 profiles. Korean J Psychosom Med. 2012;20(1):40

15. Seo HC, Oh SB, Kim TH, Lee JH, Kang SH, Lim MH. MMPI characteristics of the suicide attempter visiting emergency unit. Anxiety Mood. 2012;8(2):79-85

16. Tellegen A, Ben-Porath Y, McNulty J, Arbisi P, Graham J, Kaemmer B. MMPI-2 restructured clinical (RC) scales: development, validation, and interpretation. Minneapolis: University of Minnesota Press; 2003.

17. Ben-Porath YS, Tellegen A. Empirical correlates of the MMPI-2 restructured clinical (RC) scales in mental health, forensic, and nonclinical settings: an introduction. J Pers Assess. 2008;90(2):119-21.

18. Han KH, Moon KJ, Lim JY, Kim JS. MMPI-2-RF: manual for Korean version of MMPI-2-RF. Seoul: Maumsarang Ltd.; 2011.

19. Sellbom M, Graham JR, Schenk PW. Incremental validity of the MMPI-2 restructured clinical $(\mathrm{RC})$ scales in a private practice sample. J Pers Assess. 2006;86(2):196-205.

20. Tellegen A, Ben-Porath YS. MMPI-2-RF: Minnesota multiphasic personality inventory-2 restructured form: technical manual; 2011.

21. Simms LJ, Casillas A, Clark LA, Watson D, Doebbeling BN. Psychometric evaluation of the restructured clinical scales of the MMPI-2. Psychol Assess. 2005;17(3):345-58

22. Wallace A, Liljequist L. A comparison of the correlational structures and elevation patterns of the MMPI-2 restructured clinical (RC) and clinical scales. Assessment. 2005;12(3):290-4.

23. Arbisi PA, Sellbom M, Ben-Porath YS. Empirical correlates of the MMPI-2 restructured clinical $(\mathrm{RC})$ scales in psychiatric inpatients. J Pers Assess. 2008;90(2):122-8.

24. Sellbom M, Ben-Porath YS, Graham JR. Correlates of the MMPI-2 restructured clinical (RC) scales in a college counseling setting. J Pers Assess. 2006;86(1):88-99.

25. Castro Y, Gordon KH, Brown JS, Anestis JC, Joiner TE Jr. Examination of racial differences on the MMPI-2 clinical and restructured clinical scales in an outpatient sample. Assessment. 2008;15(3):277-86. 
26. Forbey JD, Ben-Porath YS. A comparison of the MMPI-2 restructured clinical (RC) and clinical scales in a substance abuse treatment sample. J Psychol Serv. 2007;4(1):46.

27. Megargee El. Using the MMPI-2 in criminal justice and correctional settings: An empirical approach. Minneapolis: University of Minnesota Press; 2006.

28. Gottfried E, Bodell L, Carbonell J, Joiner T. The clinical utility of the MMPI-2RF suicidal/death ideation scale. Psychol Assess. 2014;26(4):1205-11.

29. Rogers ML, Anestis JC, Harrop TM, Schneider M, Bender TW, Ringer FB, Joiner TE. Examination of MMPI-2-RF substantive scales as indicators of acute suicidal affective disturbance components. J Pers Assess. 2017:99(4):424-34.

30. Stanley IH, Yancey JR, Patrick CJ, Joiner TE. A distinct configuration of MMPI2-RF scales RCd and RC9/ACT is associated with suicide attempt risk among suicide ideators in a psychiatric outpatient sample. Psychol Assess. 2018; 30(9):1249-54

31. Glassmire DM, Tarescavage AM, Burchett D, Martinez J, Gomez A. Clinical utility of the MMPI-2-RF SUI items and scale in a forensic inpatient setting: association with interview self-report and future suicidal behaviors. Psychol Assess. 2016;28(11):1502.

32. Hawton $\mathrm{K}$, Van Heeringen $\mathrm{K}$. The international handbook of suicide and attempted suicide. Chichester, West Sussex, En- gland: Wiley; 2000.

33. Stewart D, Ross J, Watson C, James K, Bowers L. Patient characteristics and behaviours associated with self-harm and attempted suicide in acute psychiatric wards. J Clin Nurs. 2012;21(7-8):1004-13.

34. Lecrubier $Y$, Sheehan DV, Weiller E, Amorim P, Bonora I, Sheehan KH, Janavs J, Dunbar GC. The mini international neuropsychiatric interview (MINI). A short diagnostic structured interview: reliability and validity according to the CIDI. Eur Psychiatry. 1997;12(5):224-31.

35. Yoo S-W, Kim Y-S, Noh J-S, Oh K-S, Kim C-H, NamKoong K, Chae J-H, Lee GC, Jeon S-I, Min K-J. Validity of Korean version of the mini-international neuropsychiatric interview. J Anxiety Mood. 2006;2(1):50-5.

36. Sheehan DV, Lecrubier $Y$, Sheehan KH, Amorim P, Janavs J, Weiller E, Hergueta T, Baker R, Dunbar GC. The mini-international neuropsychiatric interview (MINI): the development and validation of a structured diagnostic psychiatric interview for DSM-IV and ICD-10. J Clin Psychiatry. 1998;59(20): 22-33.

37. Roaldset JO, Linaker OM, Bjørkly S. Predictive validity of the MINI suicidal scale for self-harm in acute psychiatry: a prospective study of the first year after discharge. Arch Suicide Res. 2012:16(4):287-302.

38. Spitzer RL, Williams JB, Kroenke K. Patient health questionnaire-9: J Pfizer Inc , New York: Prime MD Today; 1999.

39. Kroenke K, Spitzer RL, Williams JB. The PHQ-9: validity of a brief depression severity measure. J Gen Intern Med. 2001;16(9):606-13.

40. Park SJ, Choi HR, Choi JH, Kim KW, Hong JP. Reliability and validity of the Korean version of the patient health questionnaire-9 (PHQ-9). Anxiety Mood. 2010:6:119-24

41. Shneidman ES. Commentary: suicide as psychache. J Nerv Ment Dis. 1993;181:145-7.

42. Joiner TE Jr, Van Orden KA, Witte TK, Rudd MD. The interpersonal theory of suicide: guidance for working with suicidal clients. Washington DC: American Psychological Association; 2009.

43. Baumeister RF. Suicide as escape from self. Psychol Rev. 1990;97(1):90.

44. Ribeiro JD, Yen S, Joiner T, Siegler IC. Capability for suicide interacts with states of heightened arousal to predict death by suicide beyond the effects of depression and hopelessness. J Affect Disord. 2015;188:53-9.

45. Klonsky ED, May AM. The three-step theory (3ST): a new theory of suicide rooted in the "ideation-to-action" framework. Int J Cogn Ther. 2015;8(2):114-29.

\section{Publisher's Note}

Springer Nature remains neutral with regard to jurisdictional claims in published maps and institutional affiliations.

\section{Ready to submit your research? Choose BMC and benefit from:}

- fast, convenient online submission

- thorough peer review by experienced researchers in your field

- rapid publication on acceptance

- support for research data, including large and complex data types

- gold Open Access which fosters wider collaboration and increased citations

- maximum visibility for your research: over $100 \mathrm{M}$ website views per year

At $\mathrm{BMC}$, research is always in progress.

Learn more biomedcentral.com/submissions 